\title{
A study of English tourist guidebooks at airports in Hokuriku region in Japan
}

Hiromi Ban (Graduate School of Engineering, Nagaoka University of Technology, ban@vos.nagaokaut.ac.jp)

Takashi Oyabu (Nihonkai International Exchange Center, oyabu24@gmail.com)

\begin{abstract}
Ishikawa Prefecture is located in the Hokuriku region in Japan. One of the main targets of the tourism industry in Ishikawa is to increase the number of tourists from foreign countries. In order to achieve this goal, it is necessary to provide foreign tourists with "language service." In this study, in order to understand the state of language service provided to foreign tourists, what linguistic characteristics can be found in English guidebooks at Komatsu Airport and Toyama Airport, which are local airports in Japan, were investigated and compared with guidebooks available at international airports in Japan and the U.S. In short, frequency characteristics of character-and word-appearance were investigated using a program written in $C++$. These characteristics were approximated by an exponential function. Furthermore, the percentage of Japanese junior high school required vocabulary and American basic vocabulary was calculated to obtain the difficulty-level as well as the K-characteristic of each material. As a result, it was clearly shown that English guidebooks available at airports in the Hokuriku region have a similar tendency to literary writings in the characteristics of character-appearance. Besides, the values of the K-characteristic for the guidebooks are high, and the difficulty level is low in terms of the American basic vocabulary.
\end{abstract}

\section{Keywords}

data mining, metrical linguistics, statistical analysis, text mining, tourist guidebook

\section{Introduction}

Ishikawa Prefecture, located in the Hokuriku region in Japan, has a population of about 1.1 million, and its capital is Kanazawa city. Ishikawa is blessed with natural beauty and traditional cultures, which attract a lot of tourists. These days, one of the main targets of the tourism industry in Ishikawa is to increase the number of tourists from foreign countries. In order to achieve this goal, it is necessary to provide foreign tourists with a "language service," which motivates foreigners to go sightseeing more easily. This "language service" means to serve benefits and convenience to foreign tourists by enhancing signs, pamphlets and homepages in several languages. It will become a key word for the increase of foreign tourists [Ban and Oyabu, 2019; National Association of Language, Business and Tourism Education, 2020].

While some foreigners who visit Kyoto often extend their trip to Kanazawa which is located about two hours away by limited express train, other tourists also come to use regular flights from Seoul and Shanghai or charter flights from Taiwan to Komatsu Airport, located one hour or less away from Kanazawa city by car. Moreover, there are regular flights from Dalian to Toyama Airport which is located in the vicinity of Kanazawa, and it is likely that tourists who visit Toyama will also visit Ishikawa Prefecture.

In this study, in order to understand the state of "language service" provided to foreign tourists, English guidebooks at Komatsu Airport and Toyama Airport, which are local airports in Japan, were examined, and compared with guidebooks available at Narita, Kansai, Chubu, and San Francisco international airports. As a result, it was clearly shown that English guidebooks at local airports in Japan have some interesting characteristics regarding character- and word-appearance.

\section{Method of analysis and materials}

The materials analyzed here are English guidebooks available at Komatsu, Toyama, Narita, Kansai and Chubu. Moreover, San Francisco International Airport was taken as an example of an overseas international airport because San Francisco is a popular tourist destination in the United States. The following guidebooks were selected with paying attention to unify the topics as much as possible.

- Material 1: HOKURIKU JAPAN, Fukui, Ishikawa \& Toyama, RESORT OF WONDERS AND FASCINATION, Hot spring route blessed with four seasons, Mar. 2000, Komatsu Airport

- Material 2: TOYAMA - Japan, Oct. 2007, and TOYAMA City Guide, Nov. 2006, Toyama Airport

- Material 3: Tourist Guide, Around Narita International Airport, May 2008, Narita International Airport

- Material 4: Have a nice day in KANSAI, Visitor's guide, vol. 5, Feb. 2008, Kansai International Airport

- Material 5: Aichi, Gifu, Mie, Shizuoka, Fukui, Nagoya, ACCESS MAP, June 2007, Chubu Centrair International Airport

- Material 6: san francisco guide ${ }^{\circledR}$, where to go \& what to do, Aug. 2010, San Francisco International Airport (SFO)

Due to the circulation, the publication of Material 1 is older than other materials.

In addition, English textbooks for Japanese junior high school students (NEW HORIZON English Course 1, 2 and 3 (2010, Tokyo Shoseki Co., Ltd.) (hereinafter referred to as "JHS 1,2 and 3")) and those for Japanese high school students (UNICORN ENGLISH COURSE I, II and READING (2010, Bun-ei- 
do Publishing Co., Ltd.) (“HS 1, 2 and 3")) were also analyzed.

The computer program for this analysis is composed of $\mathrm{C}++$. Besides the characteristics of character- and word-appearance for each piece of material, various information such as the "number of sentences," the "number of paragraphs," the "mean length," the "number of words per sentence," etc. can be extracted by this program [Ban et al., 2016a].

\section{Results}

\subsection{Characteristics of character-appearance}

Zipf's law being referred to, frequencies of character- and word-appearance were examined. First, the frequently used characters in each material and their frequency were derived. The frequencies of the 50 most frequently used characters including blanks, capitals, small letters, and punctuations were plotted on a descending scale. The vertical shaft shows the degree of the frequency and the horizontal shaft shows the order of character-appearance. The vertical shaft is scaled with a logarithm. Figure 1 shows the results for Material 1.

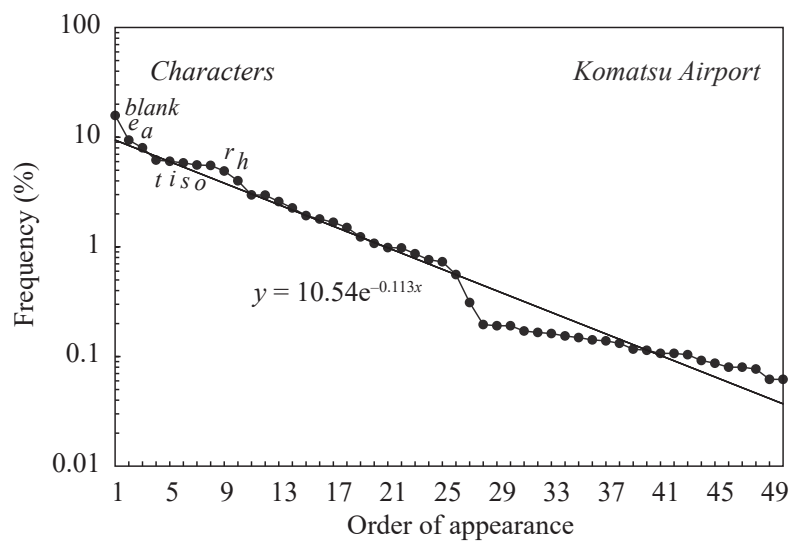

Figure 1: Frequency characteristics of character-appearance in Material 1

Between the 26th and 27th places, there is an inflection point caused by the difference in declines, and a relatively larger decline is observed at the 27 th place and thereafter. This characteristic curve was approximated by the following exponential function:

$y=c * \exp (-b x)$

From this function, coefficients $c$ and $b$ can be derived [Ban and Oyabu, 2013]. In the case of Material 1, as shown in Figure 1 , values, $c=10.54$ and $b=0.113$ were obtained.

The distribution of coefficients $\mathrm{c}$ and $\mathrm{b}$ extracted from each material is shown in Figure 2.

There is a linear relationship between $c$ and $b$ for all materials. While the values of coefficients $c$ and $b$ for Material 6 are lowest, those for HS 3, HS 2 and Material 3 are high. With regard to the English textbooks, values of $c$ and $b$ are larger for higher grades. The values for all the six tourist guidebooks are

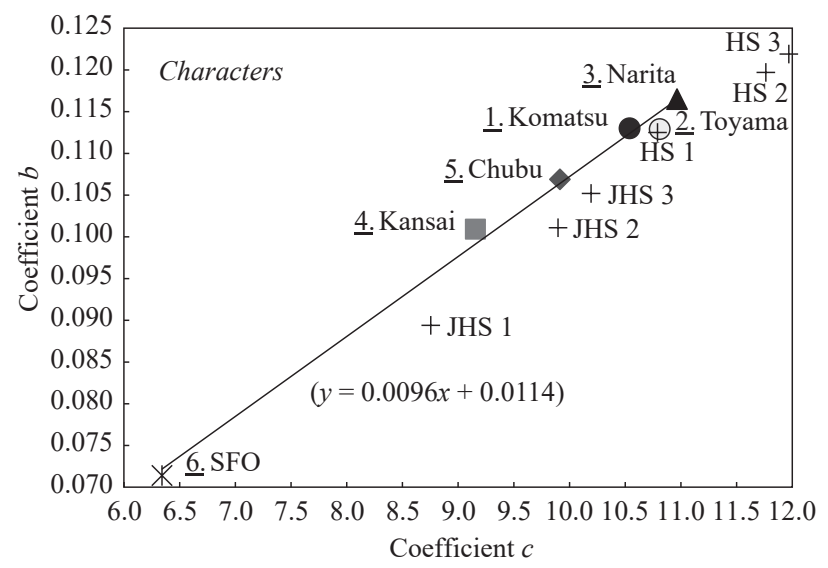

Figure 2: Dispersions of coefficients $c$ and $b$ for characterappearance

approximated by $[y=0.0096 x+0.0114]$. The values of coefficients $c$ and $b$ for Materials 1 and 2 are high: the values of $c$ are 10.540 and 10.811, and those of $b$ are 0.1130 and 0.1129 . Previously, various English writings were analyzed and it was reported that, as for the 50 most frequently used characters, there is a positive correlation between the coefficients $c$ and $b$, and that the more journalistic the material is, the lower the values of $c$ and $b$ are, and that the more literary the material is, the higher the values of $c$ and $b$ are [Ban et al., 2015a]. Thus, while the material at San Francisco International Airport is rather journalistic, the tourist guidebooks available at local airports in Japan have a similar tendency to English literary writings.

\subsection{Characteristics of word-appearance}

Next, frequently used words in each material and their frequency were derived. Table 1 shows the top 20 words most frequently used in each material. The article THE is the most frequently used word in every material except JHS 1. While $\mathrm{OF}$ is the second most frequently used word in the five guidebooks in Japan, AND is the second most frequently used word for Material 6. In the cases of Materials 1 and 2, as well as JHS 1 and JHS 2, the frequency of CAN is high, which ranks at 15 and 12 respectively. On the other hand, in the cases of Materials 3, 4 and 5, the frequencies of JAPAN and JAPANESE are high. Besides, nouns related to tourism, such as FESTIVAL in Material 1, VISITORS, TEMPLES, STREET and TRANSIT can be seen at the 8 th to 20 th in guidebooks.

Just as in the case of characters, the frequencies of the 50 most frequently used words in each material were plotted. Each characteristic curve was approximated by the same exponential function. The distribution of $c$ and $b$ is shown in Figure 3. As for the coefficient $c$, the values for Materials 1 and 2 are high: they are 1.9973 (Material 1) and 2.0042 (Material 2), compared with the value for Material 6 (1.5527). Moreover, the value of coefficient $c$ gradually increases in the order of Material 1, Material 2 and Material 3. This order corresponds with the coefficients $c$ for character-appearance, and the intervals of the val- 


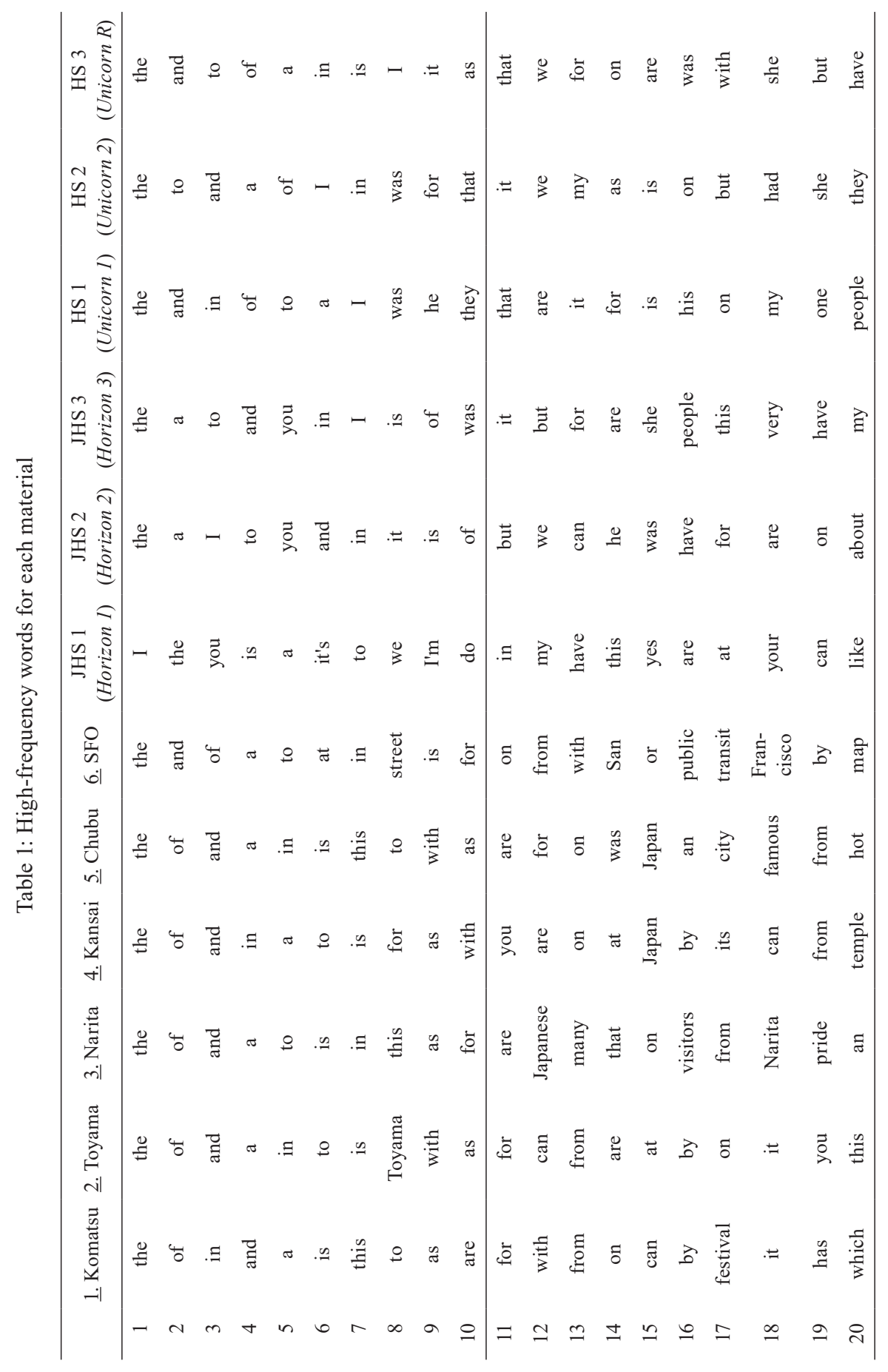




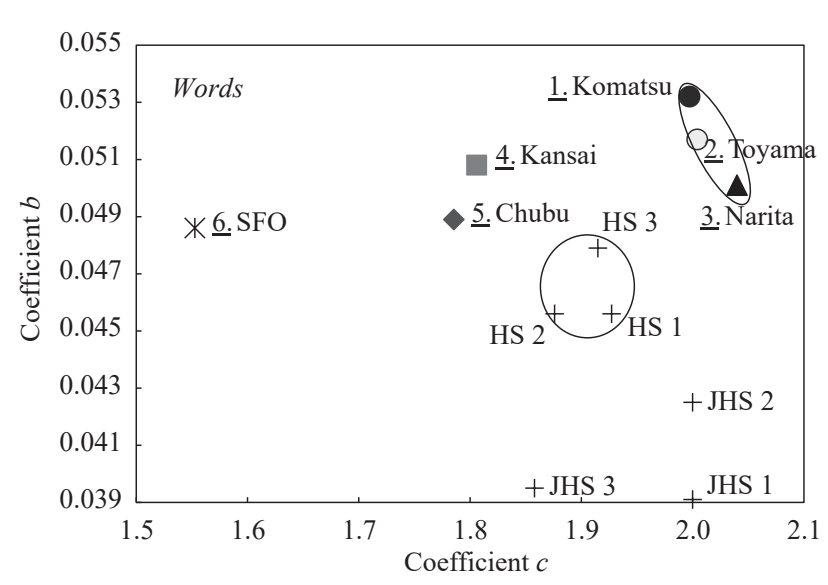

Figure 3: Dispersions of coefficients $c$ and $b$ for word-appearance

ues in both cases are very similar as well. On the hand, as for the coefficient $b$, the value for Material 1 is the highest and that for Material 2 is the second highest of all. All the six guidebooks have higher values than all the six textbooks. Besides, the values of coefficients $c$ and $b$ for word-appearance for Materials 1, 2 and 3, and those for three textbooks for high school students are similar respectively, and they might be regarded as two clusters.

As a method of featuring words used in a writing, a statistician named Udny Yule suggested an index called the " $K$-characteristic" in 1944 [Yule, 1944]. This can express the richness of vocabulary in writings by measuring the probability of any randomly selected pair of words being identical. He tried to identify the author of The Imitation of Christ using this index. This $K$-characteristic is defined as follows:

$K=10^{4}\left(S_{2} / S_{1}^{2}-1 / S_{1}\right)$

where if there are $f_{\mathrm{i}}$ words used $x_{\mathrm{i}}$ times in a writing, $S_{1}=\Sigma x_{i} f_{i}$, $S_{2}=\Sigma x_{i}^{2} f_{i}$.

The $K$-characteristic for each material was examined. The results are shown in Figure 4. According to the figure, the values for the five guidebooks in Japan are high: they range form 97.682 (Material 3) to 124.897 (Material 5), compared with the value for Material 6 (64.349), which is the lowest of all the 12 materials. The values for Materials 1 and 2 are high: they are 118.882 (Material 1) and 107.047 (Material 2), which are 54.533 and 42.678 higher than that for Material 6. As for textbooks, the values for JHS and those for HS are 70.358 to 78.935 and 79.643 to 85.488 , which are similar respectively, and the former are lower than the latter.

The results showing higher $K$-characteristics for Materials 1 and 2 than for Material 6 coincide with the aforementioned tendency regarding coefficients $c$ and $b$ for character- and wordappearance. In addition, higher $K$-characteristic values for textbooks for HS than those for JHS coincide with the tendency regarding coefficients $c$ and $b$ for character-appearance and coefficient $b$ for word-appearance. This correlation between $K$-characteristic and the coefficients for character- and wordappearance needs to be studied in the future.

\subsection{Degree of difficulty}

In order to show how difficult the materials for readers are, the degree of difficulty for each material through the variety of words and their frequency was derived [Ban et al., 2015b; Ban et al., 2016b]. That is, two parameters to measure difficulty were used; one is for word-type or word-sort $\left(D_{w s}\right)$, and the other is for the frequency or the number of words $\left(D_{w n}\right)$. The equation for each parameter is as follows:

$D_{w s}=\left(1-n_{r s} / n_{s}\right)$

$D_{w n}=\left\{1-\left(1 / n_{t} * \Sigma n(i)\right)\right\}$

where $n_{t}$ means the total number of words, $n_{s}$ means the total number of word-sort, $n_{r s}$ means the required English vocabulary in Japanese junior high schools or American basic vocabulary by The American Heritage Picture Dictionary (American Heritage Dictionaries, Houghton Mifflin, 2003), and $n(i)$ means the respective number of each required or basic word. Thus, it can be calculated how many required or basic words are not contained in each piece of material in terms of word-sort and frequency.

Thus, the values of both $D_{w s}$ and $D_{w n}$ were calculated to show how difficult the materials are for readers, and to show at which

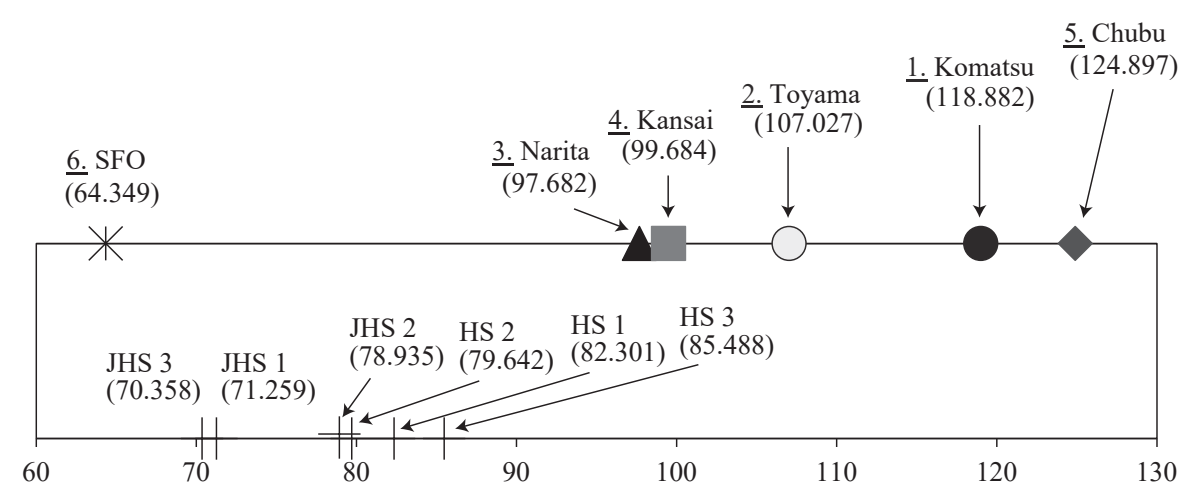

Figure 4: $K$-characteristic for each material 
level of English the materials are, compared with other materials. Then, in order to make the judgments of difficulty easier for the general public, one difficulty parameter was derived from $D_{w s}$ and $D_{w n}$ using the following principal component analysis:

$z=a_{1} * D_{w s}+a_{2} * D_{w n}$

where $a_{1}$ and $a_{2}$ are the weights used to combine $D_{w s}$ and $D_{w n}$. Using the variance-covariance matrix, the first principal component $z$ was extracted: $\left[z=0.7071 * D_{w s}+0.7071 * D_{w n}\right]$ both for required and basic vocabularies, from which the principal component scores were calculated. The results are shown in Figure 5.

According to Figure 5, all the 6 guidebooks are more difficult than English textbooks, and Material 6 is by far the most difficult of all. In the case of the required vocabulary, Material 4 is the most difficult, and Material 1 is the second most difficult of the five guidebooks in Japan. The difficulty of Material 1 is similar to that of Material 4. The difficulty level decreases in the order of Materials 4, 1, 5, 2 and 3. On the other hand, in the case of the basic vocabulary, Material 3 is the most difficult, and Material 2 is the easiest of the five guidebook materials in Japan. Material 5 is the second most difficult after Material 3, and its difficulty is almost equal to Materials 1 and 4 .

Thus, although Material 1 is difficult in the case of the Japanese required vocabulary, English guidebooks available at local airports in Hokuriku region are easy in terms of the American basic vocabulary. Therefore, the materials seem to be easier for Americans to read.

\subsection{Other characteristics}

Other metrical characteristics of each material were compared. The results of the "mean word length," the "number of words per sentence," etc. are shown in Table 2. Although the "frequency of prepositions," the "frequency of relatives," etc. were counted, some of the words counted might be used as other parts of speech because the meaning of each word was not checked.

\subsubsection{Mean word length}

As for the "mean word length," it is 5.861 letters for Material 1, which is the shortest of all the six guidebook materials. In the case of Material 2, it is 5.937 letters, which being equal to Material 4, is the third longest of all. The mean word length of Material 6 (6.004 letters) is longer than any other material. It seems that this is because Material 6 contains many longlength terms such as COLLECTION (10 times), ENTERTAINMANT (13), FISHERMAN'S (45), NEIGHBORHOOD(S) (15), RESTAURANT(S) (32) and WATERFRONT (9).

\subsubsection{Number of words per sentence}

The "number of words per sentence" for Material 1 is 17.836 words and that for Material 2 is 17.099 words. They are the second and the third longest of all the materials. All the five guidebooks in Japan have more number of words per sentence than Material 6 (14.806 words). Thus, it can be said that English tourist guidebooks at Japanese airports are characterized by a large number of words per sentence. Material 3 (18.145 words) has the highest number of all. From this point of view, as well as the result of the difficulty derived through the variety of words and their frequency in terms of the basic vocabulary, Material 3 seems to be rather difficult to read.

\subsubsection{Frequency of relatives}

The "frequency of relatives" for Material 2 is $1.414 \%$, which is the second highest, and the one for Material 1 is $1.033 \%$, which is the fourth highest of all the guidebooks. The frequency for Material 2 is as high as that for Material $3(1.540$ $\%$ ). The one for Material 5, whose percentage is only $0.472 \%$, is the lowest of all. Therefore, it can be assumed that the English guidebooks at Toyama and Narita Airports tend to contain more complex sentences, the material seems to be difficult to read from this point of view, as well as in terms of the variety

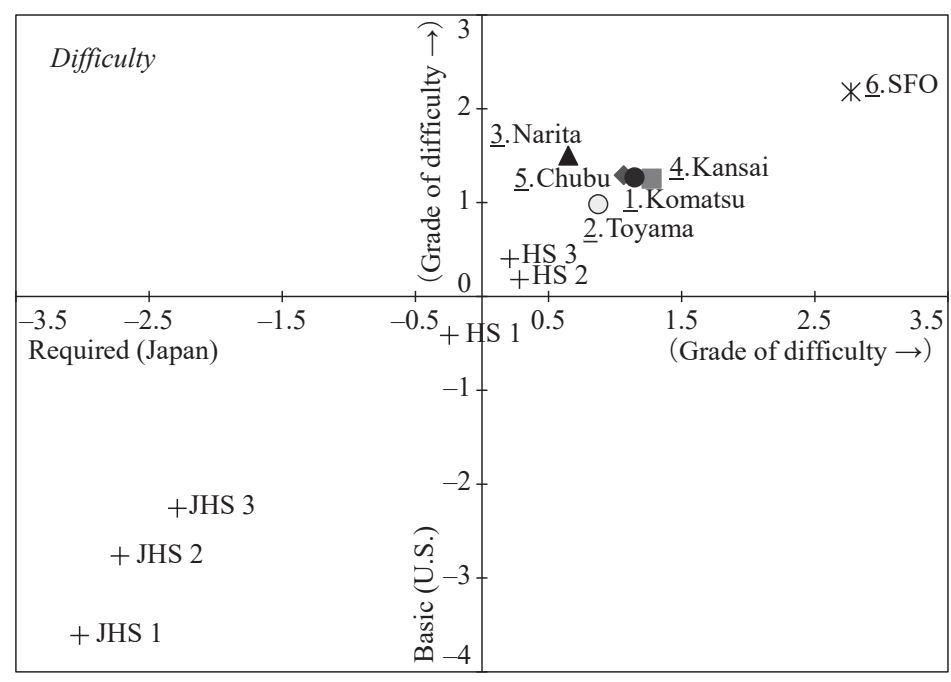

Figure 5: Principal component scores of difficulty 


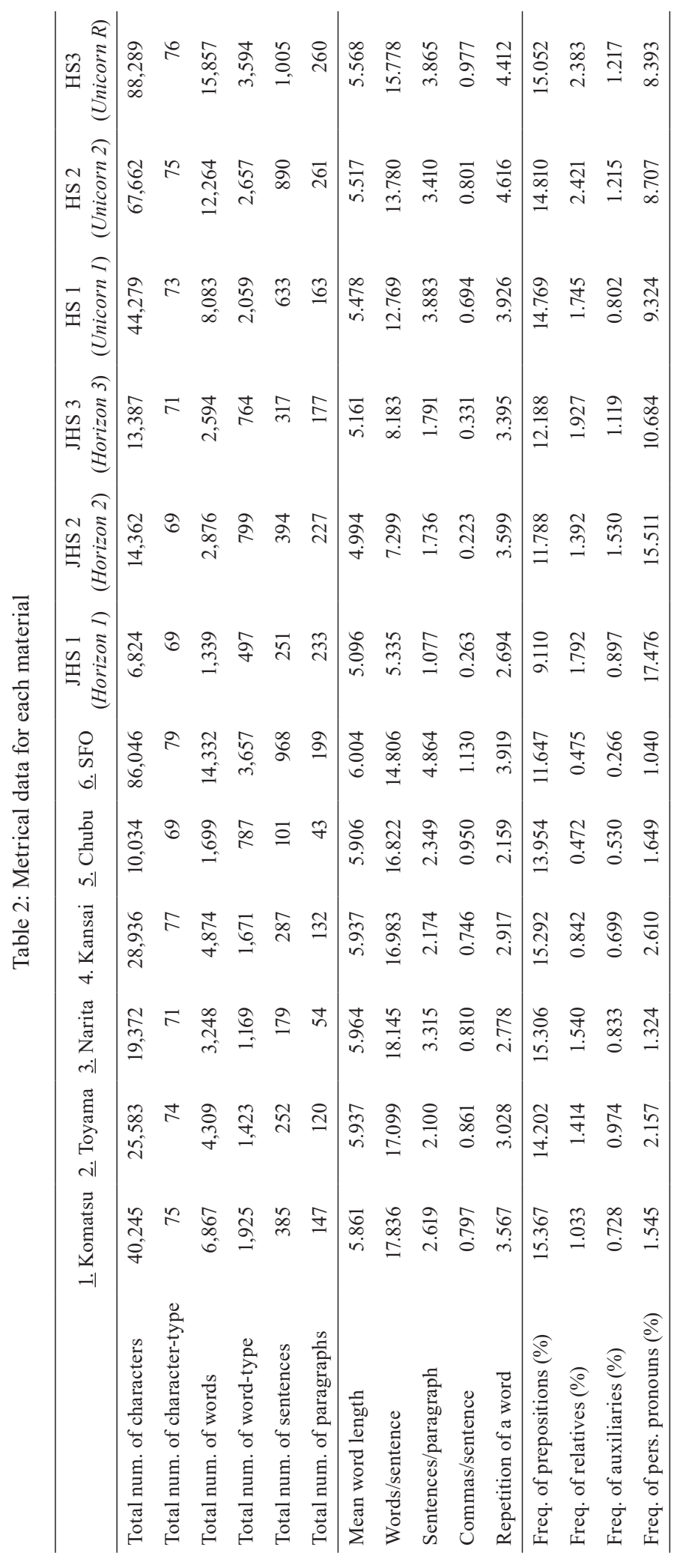


of words and their frequency.

\subsubsection{Frequency of auxiliaries}

There are two kinds of auxiliaries in a broad sense. One expresses the tense and voice, such as $\mathrm{BE}$ which makes up the progressive form and the passive form, the perfect tense $H A V E$, and $D O$ in interrogative sentences or negative sentences. The other is a modal auxiliary, such as WILL or CAN which expresses the mood or attitude of the speaker [Ban et al., 2017]. In this study, only modal auxiliaries were targeted. As a result, while the "frequency of auxiliaries" for Material $2(0.974 \%)$ is the highest and Material $1(0.728 \%)$ is the third highest of all the guidebook materials, Material 6 contains $0.266 \%$ auxiliaries, which is the lowest of all. Therefore, it might be said that while the writers of English guidebooks available at Japanese airports tend to communicate their subtle thoughts and feelings by using auxiliary verbs, the style of Material 6 can be called more assertive.

\subsection{Word-length distribution}

In addition, word-length distribution for each material was examined. The results are shown in Figure 6. The vertical shaft shows the degree of frequency with the word length as a variable. As for all the guidebook materials, the frequency of 3-letter words is the highest. The frequency of 3-letter words ranges from $17.334 \%$ (Material 3) to $21.307 \%$ (Material 5). The frequency of 5-letter words such as ENJOY, WATER and WHICH for Materials 1 and 2 is higher than in other 10 materials. While in the case of Material 1, the frequency decreases after 4-letter words, in the case of Material 2, although the frequency decreases until 7-letter words, the frequency of 8-letter words such as FESTIVAL, GOKAYAMA and VISITORS is $0.604 \%$ higher than that of 7-letter words.

Besides, although Materials 1 and 2 have almost equal frequencies to other guidebooks regarding 8-letter words, the degree of decrease for them gets a little higher than other mate- rials after 9-letter words.

\subsection{Positioning of each material}

After the aforementioned results being standardized, a positioning of all the materials was made with a principal component analysis by correlation procession. The following 22 items were considered: the values of coefficient $c$ for characterappearance, coefficient $b$ for character-appearance, coefficient $c$ for word-appearance, coefficient $b$ for word-appearance, and $K$-characteristic, the principal component scores of difficulty using the required vocabulary, and scores of difficulty using the basic vocabulary, and the total numbers of characters, character-type, words, word-type, sentences, and paragraphs, the mean word length, the numbers of words per sentence, sentences per paragraph, commas per sentence, and repetition of a word, and the frequencies of prepositions, relatives, auxiliaries, and personal pronouns. Figure 7 shows the results.

In Figure 7, both Material 1 and Material 2 are located next to Material 4. Therefore, it can be said that the literary style as a whole of the English guidebooks available at the airports in the Hokuriku region in Japan is similar to the style of the Kansai International Airport.

As for the Hokuriku region, the number of limited express trains whose departure and arrival is in the Osaka district is much larger than that for the Kanto and Chubu areas. Then, the Hokuriku region seems to have received more influence of the Kansai area. Moreover, the characteristics of spoken language in the Hokuriku region seem to be comparatively similar to those in the Kansai area. Thus, it is very interesting that also the English guidebooks analyzed in this study have more influence of the Kansai area.

\section{Conclusion}

Some characteristics of character- and word-appearance for English tourist guidebooks at local airports in Hokuriku region in Japan were investigated, compared with those for

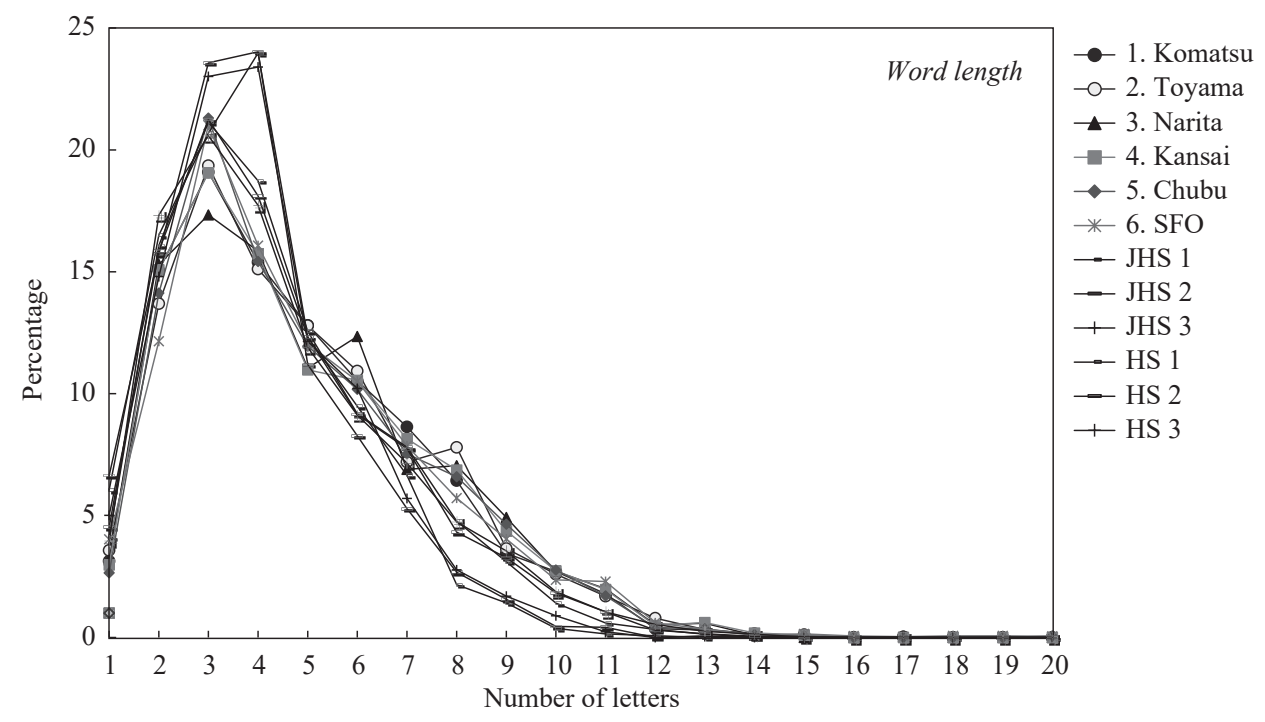

Figure 6: Word-length distribution for each material 


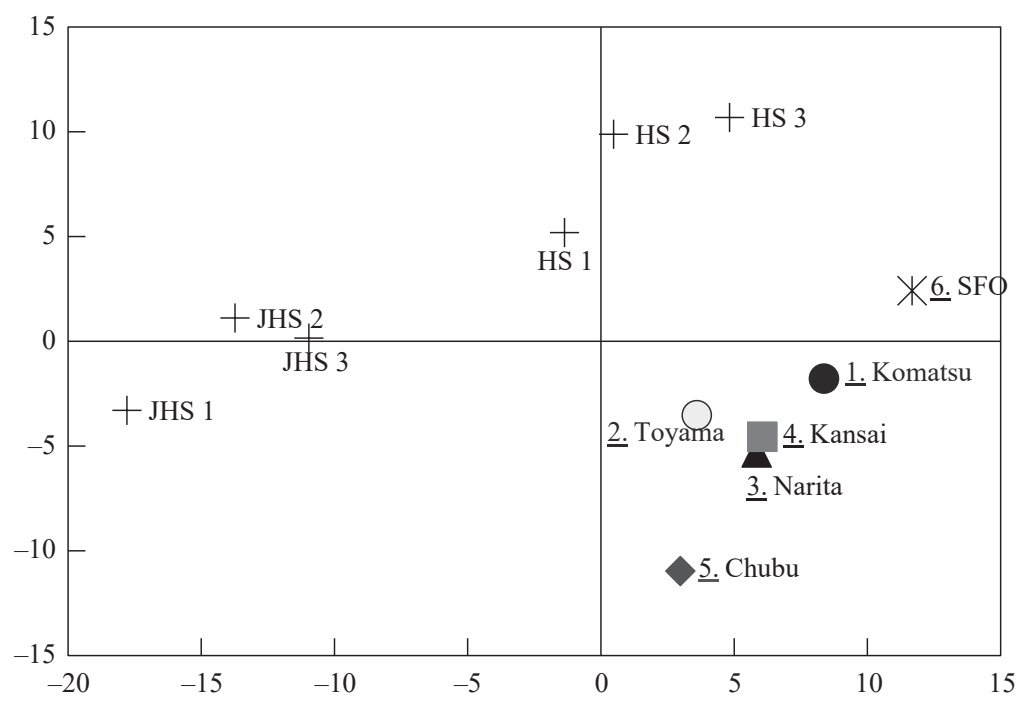

Figure 7: Positioning of each material

guidebooks available at Narita, Kansai, Chubu, and San Francisco international airports. In this analysis, an approximate equation of an exponential function was used to extract the characteristics of each material using coefficients $c$ and $b$ of the equation. Moreover, the percentage of Japanese junior high school required vocabulary and American basic vocabulary was calculated to obtain the difficulty-level as well as the $K$ characteristic. As a result, it was clearly shown that English guidebooks available at local airports in Hokuriku have a similar tendency to literary writings in the characteristics of character-appearance. Besides, the values of the $K$-characteristic for the guidebooks are high, and the difficulty level is low in terms of the American basic vocabulary.

In the future, to examine new guidebooks published after the opening of the Hokuriku Shinkansen and compare with the results educed in this study is being planned.

\section{References}

Ban, H., Kimura, H., and Oyabu, T. (2015a). Text mining of English materials for business management. International Journal of Engineering \& Technical Research, Vol. 3, No. 8, 238-243.

Ban, H., Kimura, H., and Oyabu, T. (2016a). Feature extraction of English guidebooks for Hokuriku region in Japan. Journal of Global Tourism Research, Vol. 1, No. 1, 71-76.

Ban, H., Kimura, H., and Oyabu, T. (2016b). Text mining of English articles on the Noto Hanto Earthquake in 2007. Journal of Global Tourism Research, Vol. 1, No. 2, 115-120.

Ban, H., Kimura, H., and Oyabu, T. (2017). Metrical feature extraction of English books on Tourism. Journal of Global Tourism Research, Vol. 2, No. 1, 67-72.

Ban, H., Oguri, R., and Kimura, H. (2015b). Difficulty-level classification for English writings. Transactions on Machine Learning and Artificial Intelligence, Vol. 3, No. 3, 24-32.

Ban, H. and Oyabu, T. (2013). Text data mining of English ma- terials for environmentology. International Journal of Business and Economics, Vol. 5, No. 1, 21-32.

Ban, H. and Oyabu, T. (2019). Feature extraction of the "Tourism English Proficiency Test" using data mining. Journal of Global Tourism Research, Vol. 4, No. 1, 27-34.

Ministry of Land, Infrastructure, Transport and Tourism (ed.) (2020). White paper on tourism, 2018 ed., National Printing Bureau.

Yule, G. U. (1944). The statistical study of literary vocabulary. Cambridge University Press.

(Received October 5, 2020; accepted October 31, 2020) 